\title{
ARTICLE OPEN \\ Novel equations better predict lung age: a retrospective analysis using two cohorts of participants with medical check-up examinations in Japan
}

\author{
Yasushi Ishida ${ }^{1}$, Yuri Endo Ichikawa ${ }^{2}$, Motonori Fukakusa ${ }^{3}$, Akiko Kawatsu $^{4}$ and Katsunori Masuda ${ }^{5}$
}

BACKGROUND: The lung age equations developed by the Japanese Respiratory Society encounter several problems when being applied in a clinical setting.

AIMS: To establish novel spirometry-derived lung age (SDL age) equations using data from a large number of Japanese healthy never-smokers with normal spirometric measurements and normal body mass indices (BMIs).

METHODS: The participants had undergone medical check-ups at the Center for Preventive Medicine of St Luke's International Hospital between 2004 and 2012. A total of 15,238 Japanese participants (5,499 males and 9,739 females) were chosen for the discovery cohort. The other independent 2,079 individuals were selected for the validation cohort. The original method of Morris and Temple was applied to the discovery cohort.

RESULTS: As a result of the linear regression analysis for forced expiratory volume in $1 \mathrm{~s}\left(\mathrm{FEV}_{1}\right)$, spirometric variables using forced vital capacity (FVC) improved the adjusted $R^{2}$ values to greater than 0.8 . On the basis of the scatter plots between chronological age and SDL age, the best model included the equations using $\mathrm{FEV}_{1}$ and \%FVC in females and males $\left(R^{2}=0.66\right.$ and 0.55 , respectively), which was confirmed by the validation cohort. The following equations were developed: SDL age $($ females $)=0.84 \times \% \mathrm{FVC}+50.2-$ $40 \times \mathrm{FEV}_{1}$ (I) and SDL age (males) $=1.00 \times \% \mathrm{FVC}+50.7-33.3 \times \mathrm{FEV}_{1}$ (I).

CONCLUSIONS: This study produced novel SDL age equations for Japanese adults using data from a large number of healthy never-smokers with both normal spirometric measurements and BMIs.

npj Primary Care Respiratory Medicine (2015) 25, 15011; doi:10.1038/npjpcrm.2015.11; published online 19 March 2015

\section{INTRODUCTION}

One-quarter of smokers develop chronic obstructive pulmonary disease, which is the fourth most common cause of death worldwide and is largely caused by smoking. ${ }^{1,2}$ Fukuchi et al. ${ }^{3}$ reported that the prevalence of chronic obstructive pulmonary disease in Japanese patients increased steeply in individuals aged 60 years and older, from $5.8 \%$ in those aged $50-59$ years to 15.7 and $24.7 \%$ in those aged $60-69$ years and 70 years and older, respectively. The number of patients with insidious chronic obstructive pulmonary disease is estimated to exceed five million, but more than $95 \%$ of cases are currently undiagnosed, and many of them are not treated. ${ }^{3,4}$

Spirometry can detect obstructive lung damage in susceptible individuals. ${ }^{5,6}$ Early diagnosis of chronic obstructive pulmonary disease could encourage smoking cessation and improve quit rates in individuals most vulnerable to lung damage. ${ }^{7}$ One approach used to increase the smoking cessation rate is the sharing of spirometric results with smokers. ${ }^{8}$ The concept of 'lung age' was developed in 1985 as a way of making spirometric data easier to understand for patients and also as a psychological tool to show smokers the apparent premature ageing of their lungs. ${ }^{7}$ In the original formula developed by Morris and Temple ${ }^{7}$, the regression equation constructed for predicting the reference value of forced expiratory volume in $1 \mathrm{~s}\left(\mathrm{FEV}_{1}\right)$ from age and height was rearranged to solve for 'age.' To date, several groups have reported revised equations for predicting lung age in populations worldwide. $^{8-13}$

In Japan we have often used the regression equations reported by the Japanese Respiratory Society (JRS) ${ }^{14}$ to calculate patient lung age. However, we have found that the JRS equations show a discrepancy between lung age and lung damage, especially in Japanese males. ${ }^{15}$ Occasionally, healthy males had a large lung age deficit (lung age minus chronological age), despite their status as never/non-smokers. ${ }^{2}$

The aim of the present study was to establish novel regression equations using data from a large number of healthy neversmokers with normal spirometric measurements and normal body mass indices (BMIs). The newly developed equations were validated using data obtained from another cohort of subjects.

\section{MATERIALS AND METHODS}

Study design

Two independent retrospective cohorts were used.

\section{Study population}

The participants in the discovery cohort were selected from 104,563 individuals undergoing a 1-day standardised medical check-up at the Center for Preventive Medicine of St Luke's International Hospital between January 2004 and December 2012. A questionnaire was administered to

\footnotetext{
${ }^{1}$ Pediatric Medical Center, Ehime Prefectural Central Hospital, Ehime, Japan; ${ }^{2}$ Department of Clinical Laboratory Medicine, St Luke's International Medical Center, Tokyo, Japan; ${ }^{3}$ Center for Preventive Medicine, Department of General Internal Medicine, St Luke's International Medical Center, Tokyo, Japan; ${ }^{4}$ Department of General Internal Medicine, St Luke's International Medical Center, Tokyo, Japan and ${ }^{5}$ St Luke's Affiliated Clinic, Center for Preventive Medicine, St Luke's International Medical Center, Tokyo, Japan. Correspondence: Y Ishida (yaishida2009@yahoo.co.jp)
}

Received 13 June 2014; revised 11 November 2014; accepted 2 December 2014 
subjects to obtain information about smoking status, past and present disease status and current medications. Subjects who indicated that they had never smoked before the health screening examination were identified as 'never-smokers' and comprised 63,224 patients (20,184 males and 43,040 females). The never-smokers who reported no past or present diseases, such as cardiovascular disease, cancer, hypertension, dyslipidaemia, diabetes mellitus, gout and lung disease, were identified as healthy never-smokers $(n=21,832)$. Healthy never-smokers who were taking medications at the time of the medical check-up were excluded. Among healthy never-smokers with no current medications, we included those with normal spirometric measurements: $\%^{F E V} v_{1}$ (a proportion of $\mathrm{FEV}_{1}$ divided by the forced vital capacity (FVC)) $>70 \%$ and \%FVC (a proportion of FVC divided by the predicted FVC value) $>80 \%$ and normal BMls $(18.5<\mathrm{BMI}<25.0)$. We defined them as '1-day check-up healthy never-smokers with normal spirometric measurements and normal BMIs' (Supplementary Figure 1) and enroled them as Group $1(n=15,238$, including 5,499 males and 9,739 females; Table 1).

The participants in the validation cohort were selected from an initial population of 5,595 individuals receiving a comprehensive overnight check-up at the Center for Preventive Medicine of St Luke's International Hospital between January 2004 and December 2012. Similar to the process for Group 1, we selected Japanese subjects who reported no past or present diseases as candidates for enrolment in Group 2, which constituted the study group of 'comprehensive overnight check-up healthy subjects.' A total of 2,079 participants ( $n=1,294$ males and 785 females) met the criteria and were included in the study (Table 1).

\section{Variables}

Baseline data included age at check-up, anthropometric variables (height, weight, BMI, waist circumference and blood pressure), smoking history (never/non-smoker, ex-smoker or current smoker), medical history, current medications and co-morbidities, including chronic bronchitis or emphysema, asthma or other lung diseases. All participants underwent standard measurements of lung function $\left(\mathrm{FEV}_{1}, \% \mathrm{FEV}{ }_{1}, \mathrm{FVC}\right.$ and \%FVC) with a spirometer (DISCOM-21; CHEST MI Inc., Tokyo, Japan). ${ }^{16}$
Estimation of lung age

The lung age of participants was calculated by working back from the regression equations predicting reference values of $\mathrm{FEV}_{1}$ reported by the $\mathrm{JRS}^{14}$ and our novel regression equation. The following JRS equations ${ }^{14}$ were used:

$$
\begin{aligned}
& \operatorname{FEV}_{1}(I)=0.022 \times \text { height }(\mathrm{cm})-0.022 \times \text { age }(\text { years })-0.005 \text { in females } \\
& \operatorname{FEV}_{1}(I)=0.036 \times \text { height }(\mathrm{cm})-0.028 \times \text { age }(\text { years })-1.178 \text { in males }
\end{aligned}
$$

We calculated the spirometric-derived lung age (SDL age) using the following equations:

$$
\begin{aligned}
& \mathrm{SDL}-\text { age }=\left(0.022 \times \text { height }(\mathrm{cm})-0.005-\mathrm{FEV}_{1}(\mathrm{I})\right) / 0.022 \text { in females } \\
& \mathrm{SDL}-\text { age }=\left(0.036 \times \text { height }(\mathrm{cm})-1.178-\mathrm{FEV}_{1}(\mathrm{I})\right) / 0.028 \text { in males }
\end{aligned}
$$

The lung age deficit was defined as the difference between SDL age and chronological age.

\section{Statistical analysis}

We used the original method of Morris and Temple in which the assumption is that the lung age can be expressed as a linear function of $\mathrm{FEV}_{1}$ and height $(\mathrm{cm})$. Data were analysed separately for female and male participants using multiple linear regressions and the 'enter' method. Pearson's correlation coefficients between two variables are shown in Supplementary Table 1. The difference in lung age deficits between more than three categories was analysed using the Kruskal-Wallis test, followed by multiple comparisons. Data were analysed using SPSS statistical software version 22.0 (IBM Japan, Tokyo, Japan). Two-tailed probability values $<0.05$ were considered statistically significant.

\section{Ethical considerations}

We excluded the records of individuals who had declined to participate in the clinical study. This study was approved by the Institutional Research

\begin{tabular}{|c|c|c|c|c|}
\hline & \multicolumn{2}{|c|}{ Group 1} & \multicolumn{2}{|c|}{ Group 2} \\
\hline & Females & Males & Females & Males \\
\hline Total numbers & 9,739 & 5,499 & 936 & 1,472 \\
\hline Never/non-smoker & $9,739(100 \%)$ & $5,499(100 \%)$ & $651(80.7 \%)$ & $419(31.6 \%)$ \\
\hline Ex-smoker & 0 & 0 & $104(12.9 \%)$ & $658(49.6 \%)$ \\
\hline Current smoker & 0 & 0 & $52(6.4 \%)$ & 249 (18.8\%) \\
\hline Age (years) & $42.2 \pm 9.4$ & $40.4 \pm 8.8$ & $64.2 \pm 12.9$ & $63.0 \pm 12.5$ \\
\hline$<30$ & $478(4.9 \%)$ & $445(8.1 \%)$ & $3(0.3 \%)$ & $8(0.5 \%)$ \\
\hline $30-39.9$ & $3,833(39.4 \%)$ & $2,391(43.5 \%)$ & $36(3.8 \%)$ & $52(3.5 \%)$ \\
\hline $40-49.9$ & $3,479(35.7 \%)$ & $1,886(34.3 \%)$ & $92(10.7 \%)$ & $157(10.7 \%)$ \\
\hline $50-59.9$ & $1,354(13.9 \%)$ & 583 (10.6\%) & $172(18.4 \%)$ & $335(22.8 \%)$ \\
\hline $60-69.9$ & $520(5.3 \%)$ & $172(3.1 \%)$ & $291(31.1 \%)$ & $444(30.2 \%)$ \\
\hline $70-79.9$ & $72(0.7 \%)$ & $22(0.4 \%)$ & $234(25.0 \%)$ & $336(22.8 \%)$ \\
\hline$\geqslant 80$ & $3(0.1 \%)$ & 0 & $108(11.5 \%)$ & 140 (9.5\%) \\
\hline Height $(\mathrm{cm})$ & $158.9 \pm 5.3$ & $172.2 \pm 5.8$ & $154.2 \pm 6.6$ & $168.3 \pm 6.3$ \\
\hline Weight (kg) & $52.6 \pm 5.1$ & $65.9 \pm 6.5$ & $52.3 \pm 9.5$ & $69.1 \pm 10.9$ \\
\hline $\mathrm{BMI}\left(\mathrm{kg} / \mathrm{m}^{2}\right)$ & $20.8+1.6$ & $22.2+1.6$ & $22.0+3.8$ & $24.3+3.2$ \\
\hline Waist circumference $(\mathrm{cm})$ & $74.2 \pm 5.7$ & $79.2 \pm 5.6$ & $81.3 \pm 11.2$ & $89.1 \pm 8.8$ \\
\hline Systolic blood pressure $(\mathrm{mm} \mathrm{Hg})$ & $109 \pm 13.7$ & $118 \pm 13.0$ & $121 \pm 20$ & $128 \pm 52$ \\
\hline Diastolic blood pressure $(\mathrm{mm} \mathrm{Hg})$ & $65 \pm 9.6$ & $72 \pm 9.7$ & $79 \pm 27$ & $75 \pm 21$ \\
\hline $\mathrm{FEV}_{1}(\mathrm{I})$ & $2.57 \pm 0.38$ & $3.64 \pm 0.51$ & $1.96 \pm 0.50$ & $2.70 \pm 0.68$ \\
\hline$\% \mathrm{FEV}_{1}$ & $82.9+5.8$ & $81.7+5.6$ & $75.4+7.7$ & $73.3+8.7$ \\
\hline FVC (I) & $3.09 \pm 0.43$ & $4.45 \pm 0.60$ & $2.59 \pm 0.57$ & $3.66 \pm 0.76$ \\
\hline$\% F V C$ & $112 \pm 13$ & $113 \pm 13$ & $108.8 \pm 16.8$ & $105.1 \pm 16.7$ \\
\hline
\end{tabular}
Board of St Luke's International Hospital.

Table 1. Descriptive data of the subjects in Group 1 (1-day check-up of healthy never-smokers with normal spirometric measurements and normal BMIs) and Group 2 (comprehensive overnight check-up of healthy subjects)

Data are presented as $n(\%)$ or as mean \pm s.d.

Abbreviations: BMI, body mass index; $\mathrm{FEV}_{1}$, forced expiratory volume in $1 \mathrm{~s}$; FVC, forced vital capacity; \%FEV ${ }_{1}$, percent forced expiratory volume in $1 \mathrm{~s}$; \%FVC, percent forced vital capacity. 


\section{RESULTS}

The demographic data of Group 1 and Group 2 participants are shown in Table 1. The mean age of Group 1 was about 20 years less than that of Group 2. In group 1, 75 and 78\% of subjects were between ages 30 and 50 among males and females, respectively, whereas in Group 2 this was 14 and 15\%. All subjects in Group 1 were never-smokers, whereas Group 2 included never-smokers, ex-smokers and current smokers. Height and weight were similar in the two groups, but the subjects in Group 2 had slightly higher BMIs and waist circumference compared with Group 1. The spirometric measurement values in Group 1 were higher than those in Group 2.

The scatter plots of the relationship between chronological age and $\mathrm{FEV}_{1}$ in females and males are shown in Figure 1. FEV 1 declined continuously and almost linearly over chronological ages in both females and males. FVC also declined continuously and almost linearly over chronological ages; however, there was a wider spread of data (Supplementary Figure 2).

We performed linear regression analysis for $\mathrm{FEV}_{1}$. Table 2 shows the results of the representative multiple linear regression analysis of models 1-3. Model 1 included two predictive variables (height and weight), similar to the JRS report. Model 2 was created by adding one additional variable (\%FVC) and model 3 was created with spirometric variables only (FVC (I) and \%FVC) excluding a height variable. Supplementary Table 1 shows a comparison of the other model equations; models 4, 5, 6 and 7 were created by adding one additional variable (weight (W) BMI, waist circumference, FVC, \%FVC and \%FEV 1 and FVC (I), respectively). The fitness of the model was not improved by adding the other anthropometric variables. However, the addition of FVC data significantly improved the performance of the model (the adjusted $R^{2}$ values $>0.8$ ) and multicollinearity was suspected between some variables (Supplementary Table 2).

We developed the SDL age estimation equations according to the models described above and shown in Table 2. The representative scatter plots between chronological age and SDL age are shown in Figure 2. We compared models 2 and 3 with the original JRS model. On the basis of the $R^{2}$ values, the slope (nearly equal to 1 ) and its simplicity (only two predictive variables), model 3 was considered the best model in both females $\left(R^{2}=0.66\right)$ and males $\left(R^{2}=0.55\right)$.

The box and whisker plots of lung age deficit (lung age minus chronological age) sorted by age group are shown in Figure 3. Compared with model 3 , the lung age deficit values from the JRS equations were more widely distributed, indicating a larger discrepancy between SDL age and chronological age when using the JRS method. In addition, the lung age deficit values in males tended to be positive in the JRS method, suggesting an overestimation of SDL age in all age groups, whereas the lung age deficit values using model 3 were distributed around zero in all age groups, suggesting appropriate prediction of SDL age in all age groups.

We conducted the validation study using an independent cohort (Group 2). The scatter plots of the relationships between chronological age and SDL age in never-smokers with normal spirometric measurements and normal BMls in Group 2 are shown in Figure 4. We compared model 2 and model 3 with the original JRS model. Similar to Group 1, model 3 was considered the best model in both females and males because of the values of $R^{2}$. However, the slopes of model 2 and model 3 were from 0.73 to 0.80 (there were some discrepancies to 1). The box and whisker plots of the lung age deficit according to smoking status in Group 2 are shown in Supplementary Figure 3. Similar to Group 1, the lung age deficit values distributed more widely in the JRS method compared with model 3.

\section{DISCUSSION}

Main findings

This study produced the following novel SDL age equations using data from a large number of healthy never-smokers with normal spirometric measurements and normal BMIs: SDL age (females) = $0.84 \times \% \mathrm{FVC}+50.2-40 \times \mathrm{FEV}_{1}(\mathrm{I})$, and SDL age (males) $=1.00 \times \%$ $\mathrm{FVC}+50.7-33.3 \times \mathrm{FEV}_{1}$ (I).

Interpretation of findings in relation to previously published work The JRS ${ }^{14}$ has developed standardised equations for determining the lung age in the Japanese population based on the original method of Morris and Temple. ${ }^{7}$ However, several problems have been noted for the JRS equations. First, these equations were not validated with a large number of Japanese subjects. ${ }^{9,17}$ Second, the JRS equations produced discrepant results between lung age and lung damage, especially in Japanese males. ${ }^{15}$ Occasionally, healthy males who were healthy never-smokers showed a large lung age deficit. In addition, it is not self-evident whether lung age can be reliably predicted from the single spirometric parameter of $\mathrm{FEV}_{1} \cdot{ }^{17}$

To our knowledge, several groups have reported revised equations predicting lung age in worldwide populations. ${ }^{8-13}$ The American Thoracic Society guidelines for spirometry recommend that predictive equations be derived from a 'relevant' population ${ }^{18}$ and should be updated at least every 10 years. ${ }^{19}$ The lung age equations currently used in Japan were developed by the JRS in $2001 i^{14}$ thus, adequately updated equations using data from
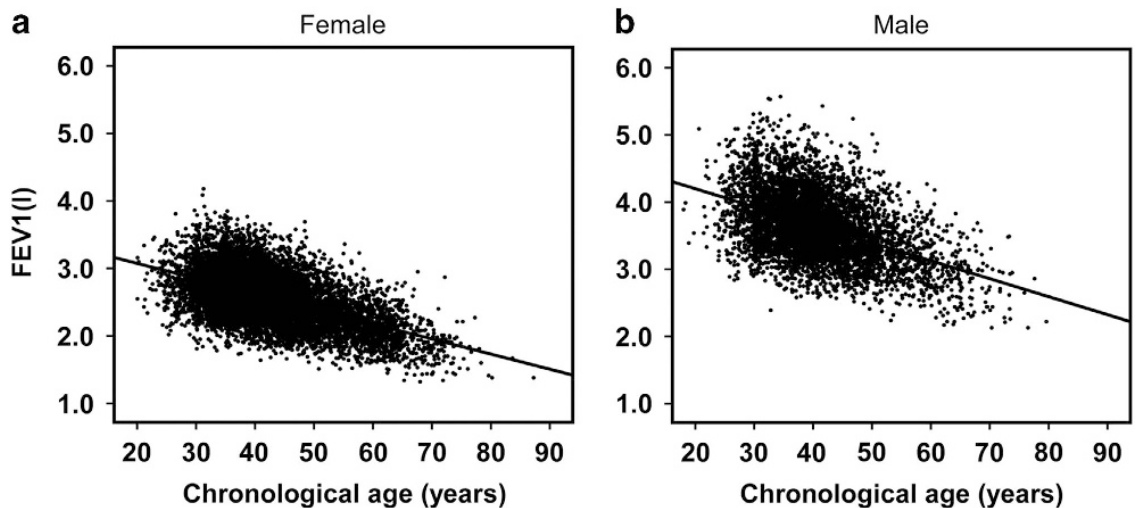

Figure 1. The scatter plots between chronological age (years) and $\mathrm{FEV}_{1}(\mathrm{I})$ in females and males in Group 1. Scatter plots showing the relationship between chronological age and $\mathrm{FEV}_{1}$ in $(\mathbf{a})$ females $(n=9,739)$ and $(\mathbf{b})$ males $(n=5,499)$ in Group 1 . The line of best fit for FEV $1(y)$ against chronological age $(x)$ is expressed by a solid line. 
Table 2. Model equations by multiple linear regression analysis

\begin{tabular}{|c|c|c|c|c|c|c|}
\hline & Adjusted $\mathrm{R}^{2}$ & Height B ( $\beta)$ & Age B ( $\beta)$ & Constant & Other variable B ( $\beta)$ & P-value of other variable \\
\hline Model 1 & \multicolumn{6}{|c|}{$\begin{array}{l}\text { Equation: } \mathrm{FEV}_{1}(\mathrm{I})=0.030 \times \text { height }(\mathrm{cm})-0.018 \times \text { age }(\text { years })-1.424 \\
\mathrm{SDL} \text { age }=1.67 \times \text { height }(\mathrm{cm})-55.6 \times \mathrm{FEV}_{1}(\mathrm{I})-79.1\end{array}$} \\
\hline Model 2 & \multicolumn{6}{|c|}{$\begin{array}{l}\text { Equation: } \mathrm{FEV}_{1}(\mathrm{I})=0.015 \times \text { height }(\mathrm{cm})-0.023 \times \text { age }(\text { years })-1.087+0.019 \times \% \mathrm{FVC} \\
\mathrm{SDL} \text { age }=0.65 \times \text { height }(\mathrm{cm})-43.5 \times \mathrm{FEV}_{1}(\mathrm{I})-47.3+0.83 \times \% \mathrm{FVC}\end{array}$} \\
\hline Model 3 & $\begin{array}{l}\quad 0.800 \\
\text { Equation: } \mathrm{FE} \\
\mathrm{SDL} \text { age }=-\end{array}$ & $\begin{array}{l}=-0.025 \times \text { age } \\
\text { FEV }_{1}(\mathrm{l})+50.2+0\end{array}$ & $\begin{array}{l}-0.025(-0.609) \\
\text { rs) }+1.256+0.021 \times \\
\% \text { FVC }\end{array}$ & 1.256 & \%FVC 0.021 (0.708) & $<0.001$ \\
\hline \multicolumn{7}{|l|}{ Male } \\
\hline Model 1 & \multicolumn{6}{|c|}{$\begin{array}{l}\text { Equation: } \mathrm{FEV}_{1}(\mathrm{I})=0.040 \times \text { height }(\mathrm{cm})-0.018 \times \text { age }(\text { years })-2.383 \\
\mathrm{SDL} \text { age }=2.22 \times \text { height }(\mathrm{cm})-45.5 \times \mathrm{FEV}_{1}(\mathrm{I})-132.3\end{array}$} \\
\hline Model 3 & $\begin{array}{l}0.767 \\
\text { Equation: } \mathrm{FE} \\
\mathrm{SDL} \text { age }=-\end{array}$ & $\begin{array}{l}=-0.030 \times a g \\
\times \mathrm{FEV}_{1}(\mathrm{I})+50.7+\end{array}$ & $\begin{array}{l}-0.030(-0.525) \\
\text { rs) }+1.522+0.030 \times \\
\times \% \text { FVC }\end{array}$ & 1.522 & \%FVC $0.030(0.744)$ & $<0.001$ \\
\hline
\end{tabular}

Abbreviations: $B$ and $\beta$, regression coefficients; FEV , forced expiratory volume in $1 \mathrm{~s} ; \mathrm{FVC}$, forced vital capacity; NA, not available; SDL age, spirometry-derived lung age; $\% \mathrm{FEV}_{1}$, percent forced expiratory volume in $1 \mathrm{~s} ; \% \mathrm{FVC}$, percent forced vital capacity.
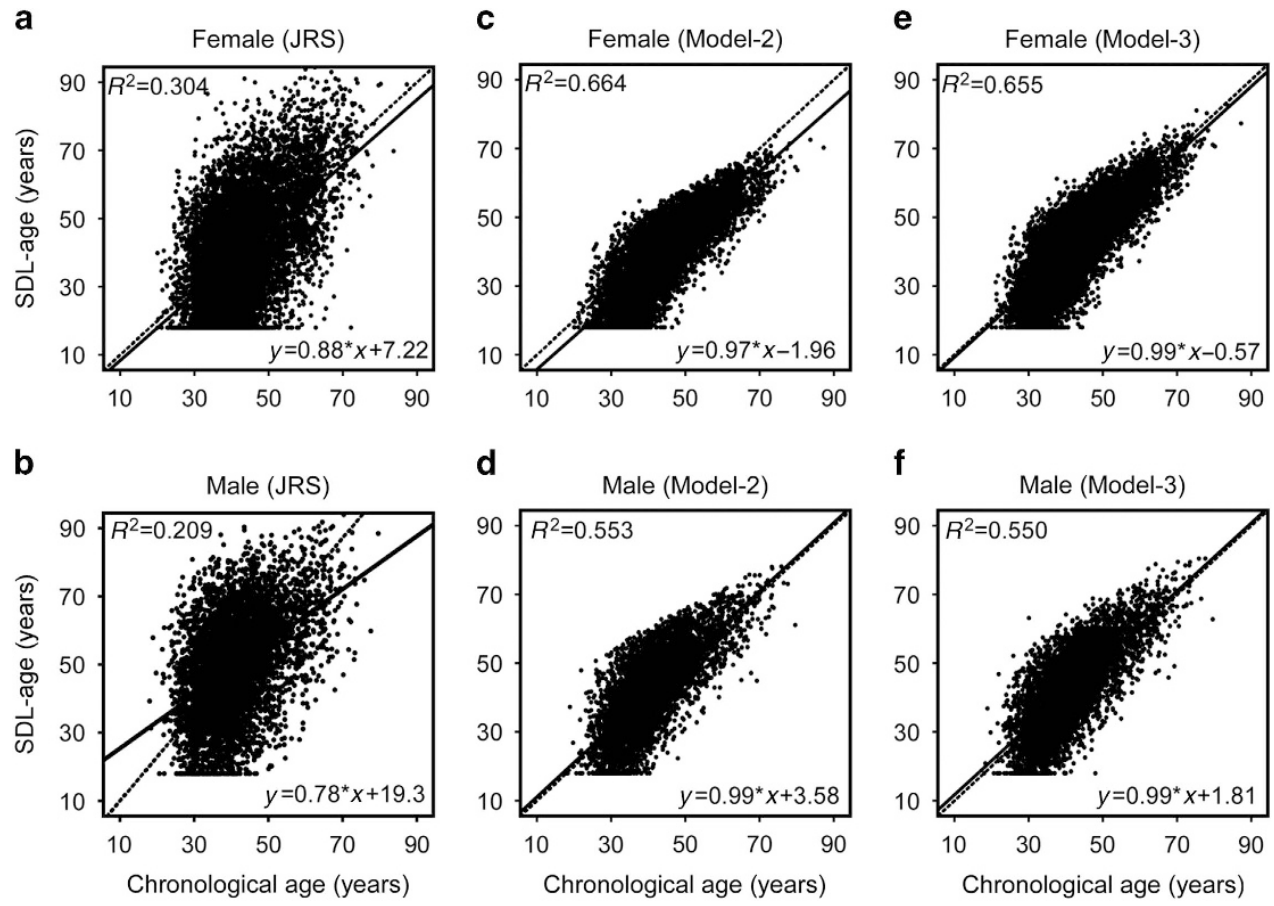

Figure 2. Scatter plots between chronological age (years) and SDL age (years) in Group 1. Scatter plots showing the relationship between chronological age and SDL age in Group 1. SDL age was determined in females and males according to the JRS equations (a and b, respectively), model 2 equations ( $\mathbf{c}$ and $\mathbf{d}$, respectively) and model 3 equations (e and $\mathbf{f}$, respectively). The lines of best fit for SDL age ( $y$ ) against chronological age $(x)$ are expressed by solid lines. Dotted lines indicate identity lines $(y-x)$.

the Japanese population will be indispensable for appropriate evaluation of lung age.

We developed candidate regression models using the original methods of Morris and Temple. ${ }^{7}$ Thereafter, we compared alternative regression models by adding one more variable. The fitness of the model was not improved by adding the other anthropometric variables, but the addition of FVC information improved the adjusted $R^{2}$ values significantly. Models 2 and 3 had 
a

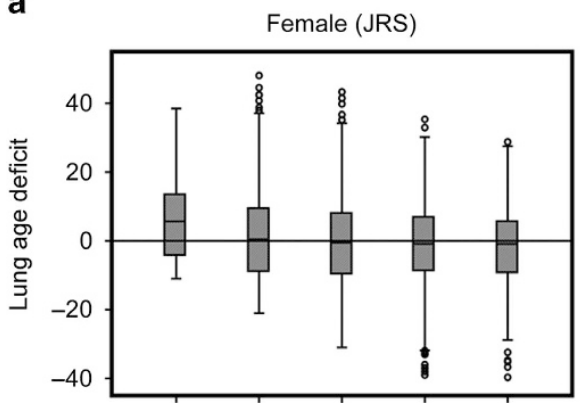

b

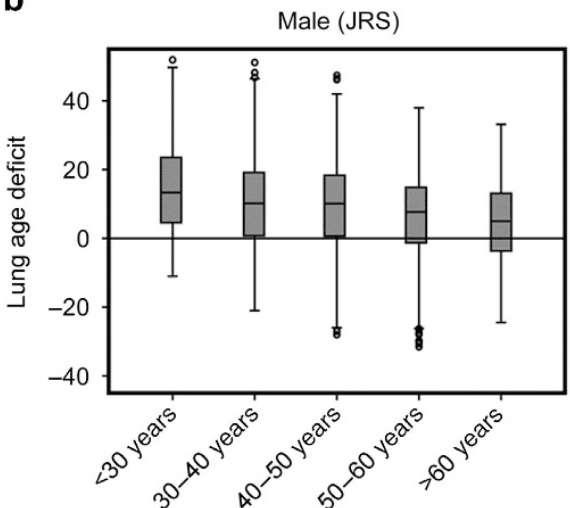

C

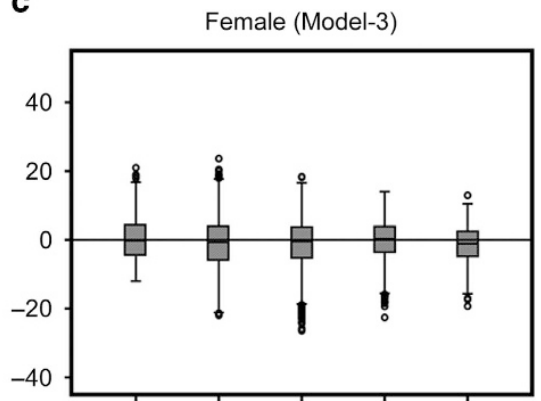

d

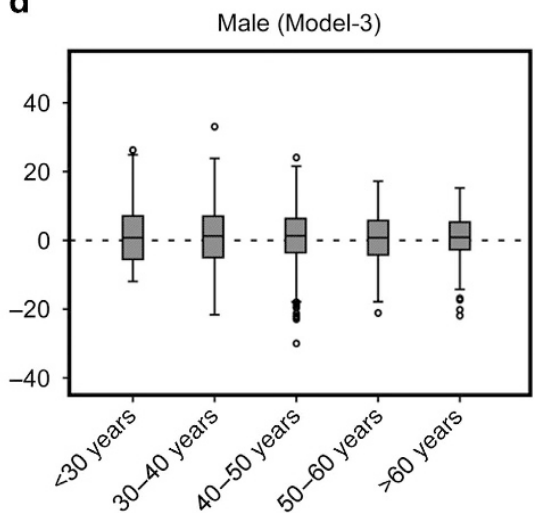

Figure 3. The box plots of lung age deficit (SDL ages minus chronological age) sorted by age in Group 1. Box and whisker plots of SDL age deficit (SDL ages minus chronological age) according to age in Group 1. SDL age was determined in females and males according to the JRS equations ( $\mathbf{a}$ and $\mathbf{b}$, respectively) and model 2 equations (c and $\mathbf{d}$, respectively). The bottom and top of the box represent the first and third quartiles, and the thick band inside the box represents the median. The ends of the whiskers represent the first and third quartiles, and the thick band inside the box represents the median. The ends of the whiskers represent the minimum and maximum of all data within 1.5 times the interquartile range from the bottom or the top of the box. Circles represent outliers.

a

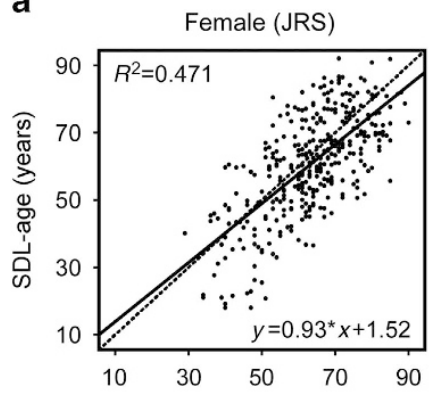

b

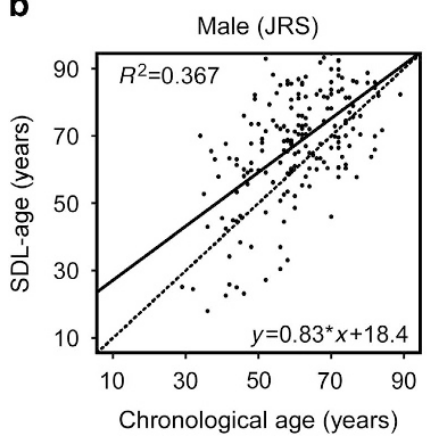

c

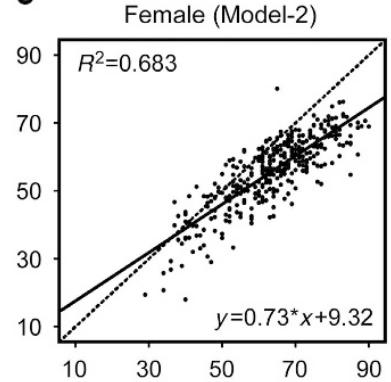

d

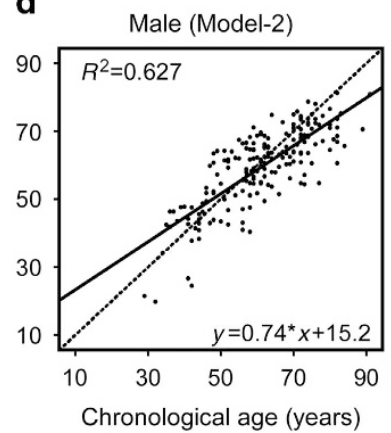

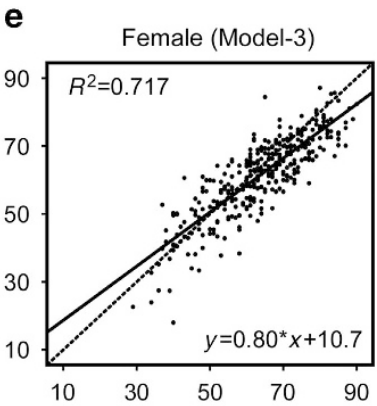

f

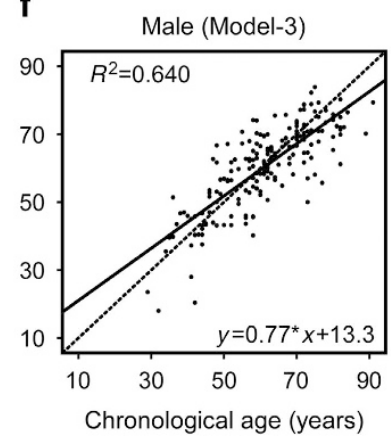

Figure 4. The scatter plots between chronological age (years) and SDL age (years) in non-smokers with normal spirometric measurements and normal BMI in Group 2. Scatter plots between chronological age and SDL age in never/non-smokers with normal spirometric measurements and BMIs in Group 2. SDL age was determined in females and males according to the JRS equations ( $\mathbf{a}$ and $\mathbf{b}$, respectively), model 2 equations (c and $\mathbf{d}$, respectively) and model 3 equations (e and $\mathbf{f}$, respectively). The lines of best fit for SDL age (y) against chronological age ( $x$ ) are expressed by solid lines. Dotted lines indicate identity lines $(y=x)$. 
a comparable ability for predicting SDL age; however, we selected model 3 as the best model because, first, the ideal equations should be as simple as possible and, second, because model 3 in both females and males revealed not only higher values of $R^{2}$ but also nearer to 1 as the slopes in the validation cohort (Group 2).

\section{Strengths and limitations of this study}

One strength of the current study is that our model was developed using a large sample size $(n=15,238)$ of healthy never-smokers with normal spirometric measurements and normal BMls. In addition, these SDL age equations used two different spirometric parameters, $\mathrm{FEV}_{1}$ and $\% \mathrm{FVC}^{20}$ It is well known that these two values reflect different aspects of lung damage. We also validated this model in an independent cohort group.

The results of this study should be interpreted in the context of the acknowledged limitations. First, this study was conducted in only one hospital (St Luke's International Hospital), and the socioeconomic status of our participants does not seem to be representative of the general population of Japanese patients. Our participants might consist of higher-income upper-class individuals, with white collar occupations. However, data on occupational and other environmental exposure were not available in this study. Second, Yomaguchi et al., ${ }^{9,17}$ suggested that the simple backward calculation of age from the regression equation for the reference value of $\mathrm{FEV}_{1}$ may not be appropriate from statistical points of view.

Implications for future research, policy and practice

We used contemporary data to produce novel SDL age equations for Japanese adults aged 18-80 years. International guidelines suggest that lung function equations should be derived from the same population to which they will be applied and should be updated regularly. Appropriate SDL age equations can be used to give a more powerful message to motivate people to quit smoking. Further research is needed to validate these equations using other populations with large sample sizes.

\section{Conclusions}

We developed novel SDL age equations using $\mathrm{FEV}_{1}$ and \%FVC from 15,238 Japanese healthy never-smokers with normal spirometric measurements and BMI.

\section{ACKNOWLEDGEMENTS}

We sincerely thank Ms Kazumi Ishida for her secretarial assistance and Ms Yoko Sakuma and Kyoko Takeda for their supervision.

\section{CONTRIBUTIONS}

YI was responsible for the conception and design of the study and the financial support. AK and KM provided administrative support. YEI and MF provided the study patients and collected and assembled the data. YI, YEI and MF provided data analysis and data interpretation. YI wrote the manuscript. All authors were responsible for the final approval of the manuscript.

\section{COMPETING INTERESTS}

The authors declare no conflict of interest.

\section{FUNDING}

This study was supported in part by a research grant from the St Luke's Life Science Institute.

\section{REFERENCES}

1 Parkes G, Greenhalgh T, Griffin M, Dent R. Effect on smoking quit rate of telling patients their lung age: the Step2quit randomised controlled trial. BMJ 2008; 336: 598-600.

2 Young RP, Hopkins R, Eaton TE. Forced expiratory volume in one second: not just a lung function test but a marker of premature death from all causes. Eur Respir $J$ 2007; 30: 616-622.

3 Fukuchi $Y$, Nishimura M, Ichinose M, Adachi M, Nagai A, Kuriyama $T$ et al. COPD in Japan: the Nippon COPD Epidemiology study. Respirology 2004; 9 458-465.

4 Takahashi T, Ichinose M, Inoue H, Shirato K, Hattori T, Takishima T. Underdiagnosis and undertreatment of COPD in primary care settings. Respirology 2003; 8: 504-508.

5 Zirlik S, Wich C, Frieser M, Hildner K, Kleye C, Neurath MF et al. Public spirometry for primary prevention of COPD. J Eval Clin Pract 2013; 20: 43-47.

6 Drummond MB, Hansel NN, Connett JE, Scanlon PD, Tashkin DP, Wise RA. Spirometric predictors of lung function decline and mortality in early chronic obstructive pulmonary disease. Am J Respir Crit Care Med 2012; 185: 1301-1306.

7 Morris JF, Temple W. Spirometric 'lung age' estimation for motivating smoking cessation. Prev Med 1985; 14: 655-662.

8 Newbury W, Newbury J, Briggs N, Crockett A. Exploring the need to update lung age equations. Prim Care Respir J 2010; 19: 242-247.

9 Yamaguchi K, Omori H, Onoue A, Katoh T, Ogata Y, Kawashima H, Onizawa S, Tsuji T, Aoshiba K, Nagai A. Novel regression equations predicting lung age from varied spirometric parameters. Respir Physiol Neurobiol 2012; 183: 108-114.

10 Toda R, Hoshino T, Kawayama T, Imaoka H, Sakazaki Y, Tsuda T et al. Validation of 'lung age' measured by spirometry and handy electronic FEV1/FEV6 meter in pulmonary diseases. Intern Med 2009; 48: 513-521.

11 Cruz-Merida AJ, Soto-de la Fuente AE, Mendez-Vargas MM, Mendez-Ramirez I. Prediction equations for spirometric parameters in Mexican adult population. Arch Med Res 2004; 35: 446-449.

12 Hankinson JL, Odencrantz JR, Fedan KB. Spirometric reference values from a sample of the general U.S. population. Am J Respir Crit Care Med 1999; 159: 179-187.

13 Gore CJ, Crockett AJ, Pederson DG, Booth ML, Bauman A, Owen N. Spirometric standards for healthy adult lifetime nonsmokers in Australia. Eur Respir J 1995; 8: 773-782.

14 The Report of the Special Committee of Pulmonary Physiology of the Japanese Respiratory Society (JRS). Reference values for spirogram and blood gas analysis in non-smoking healthy adults in Japan. J Jpn Respir Soc 2001; 39: 1-17, (In Japanese).

15 Fukakusa M, Ishida Y, Masuda K. Lung age are an adequate tool for obtaining quit smoking in any smokers (Meeting Abstracts). Am J Respir Crit Care Med 2013; 187: A3148.

16 Miller MR, Hankinson J, Brusasco V, Burgos F, Casaburi R, Coates A et al. Standardisation of spirometry. Eur Respir J 2005; 26: 319-338.

17 Yamaguchi K, Onizawa S, Tsuji T, Aoshiba K, Nagai A. How to evaluate 'spirometric' lung age--what method is approvable? Respir Physiol Neurobiol 2011; 178: 349-351.

18 American Thoracic Society. Lung function testing: selection of reference values and interpretative strategies. Am Rev Respir Dis 1991; 144: 1202-1218.

19 Pellegrino R, Viegi G, Brusasco V, Crapo RO, Burgos F, Casaburi R et al. Interpretative strategies for lung function tests. Eur Respir J 2005; 26: 948-968.

20 Golczewski T, Lubiński W, Chciałowski A. A mathematical reason for FEV1/FVC dependence on age. Respir Res 2012; 13: 57.

\section{(i) (2) (1)}

This work is licensed under a Creative Commons AttributionNonCommercial-ShareAlike 4.0 International License. The images or other third party material in this article are included in the article's Creative Commons license, unless indicated otherwise in the credit line; if the material is not included under the Creative Commons license, users will need to obtain permission from the license holder to reproduce the material. To view a copy of this license, visit http:// creativecommons.org/licenses/by-nc-sa/4.0/

Supplementary Information accompanies the paper on the npj Primary Care Respiratory Medicine website (http://www.nature.com/npjpcrm) 